\title{
autêntica
}

\author{
ARTIGOS
}

\section{O projeto colaborativo obeduc/UFMT/ e seus desdobramentos em redes de estudos e pesquisa}

Simone Albuquerque da Rocha

\begin{abstract}
RESUMO
O artigo socializa as atividades de estudos e pesquisas em redes de ensino e de colaboração desenvolvidas pelo projeto OBEDUC/CAPES/INEP/SECADI a partir de sua aprovação no edital n.49 de 2013, tendo o início de suas atividades em 2014 no Programa de Pós-Graduação em Educação na UFMT/Câmpus de Rondonópolis (CUR). A proposta do projeto objetiva levantar, analisar e propor alternativas para o que apresentam os professores em início de carreira acerca de seus dilemas, enfrentamentos, desafios e necessidades formativas. O OBEDUC/UFMT /CUR delegou aos professores a autoria da pauta de sua formação e nesse processo a articulação entre a coordenação, os mestrandos, os graduandos e as escolas, envolve as redes municipal e estadual de ensino. Deste projeto colaborativo surgem as pesquisas dos envolvidos a partir dos estudos coletivos em redes de formação, resultando em produções que subsidiam e fomentam temas pouco explorados nessa área. Evidenciou-se ainda que a participação das escolas e de seus professores iniciantes tem modificado a cultura de inserção dos iniciantes no campo do trabalho docente.
\end{abstract}

PALAVRAS-CHAVE

OBEDUC. Formação de Professores iniciantes. Projeto colaborativo e redes de pesquisa.

\section{THE COLLABORATIVE PROJECT OBEDUC/UFMT/CUR AND ITS DEVELOPMENTS IN NETWORKS OF STUDIES AND RESEARCH}

\begin{abstract}
The article socializes the activities of studies and research in the networks of teaching and of collaboration developed by the project OBEDUC/CAPES/INEP/SECADI from its approval in the public notice number 49 of 2013, having the outset of its activities in 2014 in the Program of Graduate Studies in Education in the UFMT (Federal University of Mato Grosso) campus of Rondonópolis (CUR). The proposal of the project aims to collect, analyze and offer alternatives to what is presented by the teachers in early career regarding their dilemmas, confrontations, challenges and teaching needs. The OBEDUC/UFMT /CUR delegated the teachers the authorship of the agenda of their development and in this process the articulation between the coordination, the graduate students, the undergraduate students and the schools, involve the municipal and state network of teaching. From this collaborative project arises the research of the involved with the collective studies in networks of teaching, resulting in productions that subsidize and promote themes remotely explored in this area. It was also confirmed that the participation of the schools and of its beginner teachers have modified the culture of entry of the beginners in the teaching field of work.
\end{abstract}

\section{KEY-WORDS:}

OBEDUC. Beginner Teacher development. Collaborative work and networks of research. 


\section{DELINEANDO O PROJETO OBEDUC DO PPGEDU/UFMT}

A formação de professores tem sido objeto de discussão por parte de pesquisadores e estudiosos, assim como por sistemas, fundações e órgãos de fomento que investem no financiamento de projetos e programas com a finalidade de acompanhar, analisar, avaliar, registrar trajetórias e práticas de melhor aprender a aprender e aprender a ensinar.

Entre tais propostas, destaca-se o Observatório da Educação - OBEDUC/CAPES que tem subsidiado projetos por meio de editais ao longo dos últimos dez anos, sendo instituído pelo Decreto Presidencial de $\mathrm{n}^{\circ}$ $5.803 / 2006$, como um programa de fomento ao desenvolvimento de estudos e pesquisas em educação. Conforme o estabelecido no parágrafo $2^{\circ}$ da Portaria Obeduc n. ${ }^{\circ} 152 / 12$, "os projetos submetidos ao OBEDUC devem incentivar a articulação entre pós-graduação, licenciaturas e escolas de educação básica" por meio de financiamento específico, definido por dotações orçamentárias anualmente consignadas ao Ministério da Educação, à Coordenação de Aperfeiçoamento de Pessoal de Nível Superior ( CAPES), ao Instituto Nacional de Estudos e Pesquisas Educacionais Anísio Teixeira (INEP) e à Secretaria de Educação Continuada, Alfabetização, Diversidade e Inclusão (SECADI).

Mediante essa possibilidade de ter um projeto subsidiado nos moldes supracitados, docente vinculado ao Programa de Pós-Graduação em Educação da Universidade Federal de Mato Grosso, do Câmpus Universitário de Rondonópolis - PPGEdu/UFMT/CUR -, apresentou o projeto intitulado "Egressos da Licenciatura em Pedagogia e os desafios da prática em narrativas: a universidade e a escola em um processo interdisciplinar de inserção do professor iniciante na carreira docente", que foi submetido e aprovado por meio do Edital $n^{\circ}$ 49/2012 no OBEDUC.

A equipe responsável pelo desenvolvimento desse projeto é composta por uma coordenadora (Simone Albuquerque da Rocha), quatro mestrandos, seis professores que atuam em seis escolas de educação básica e seis graduandos, todos bolsistas do OBEDUC. Colaboram, também, com o desenvolvimento do projeto, sem o subsídio de bolsas, um professor institucional e professores de outras instituições, sendo eles: um da Unviersidade do Minho em Portugal (UMinho-PT), um da Universidade federal do Rio Grande do Sul (UFRGS) e um da universidade federal de Manaus (UFAM).

As escolas que participam do projeto são selecionadas a partir do critério de terem, em seu corpo docente, minimamente, quatro professores iniciantes. Esse critério fora estabelecido de forma a ser atendido o objetivo do projeto, que tenciona compreender o processo de constituição da identidade profissional docente dos egressos do Curso de Pedagogia, em um estudo longitudinal que acompanha os sujeitos desde a formação inicial e tem sua continuidade nos anos iniciais da docência, evidenciando dificuldades, impasses, desafios narrados em "escritas de si" e trabalhados em momentos de socialização e formação como proposta de inserção do profissional no ambiente de trabalho, com a interdisciplinaridade permeando a proposta (Projeto PPGEdu/UFMT/OBEDUC, 2013, p. 3). Os objetivos específicos buscam registrar quais sentidos os professores iniciantes atribuem à formação coletiva desenvolvida no OBEDUC/UFMT e de que forma evidenciam os reflexos dessa formação em seu desenvolvimento profissional.

Traçados os objetivos as questões que movem a pesquisa são: Que dificuldades e desafios apresentam os professores iniciantes das escolas públicas de Rondonópolis/UFMT? Que necessidades formativas constituem sua agenda de formação? É possível que um projeto colaborativo Universidade/escola contribua para amenizar seus impasses e desafios? Que sentidos os iniciantes atribuem à formação do OBEDUC/UFMT em relação ao seu desenvolvimento profissional? 
O projeto trabalha com a formação de professores iniciantes de diferentes escolas que têm, em comum, suas práticas permeadas por diversas dificuldades e desafios característicos dessa fase. Dessa forma, tais práticas são tratadas coletivamente em reuniões de formação, nas quais o foco central são os iniciantes e a autoria de sua agenda de necessidades formativas. Caracteriza-se, assim, como um grupo de pertença posto que trata-se de novos profissionais que somam-se à formação com as mesmas características - de serem professores iniciantes, compartilharem das mesmas dificuldades, dilemas e desafios e poderem contar (no caso deste projeto) com a gestão da escola nas discussões de seus problemas.

Para o acompanhamento aos professores iniciantes, há o professor da escola básica que denomina-se no projeto como professor experiente. Este, igualmente, desenvolve sua formação no OBEDUC/UFMT e tem a função de apoiar, acompanhar o iniciante em seus desafios e necessidades. Conforme pontuam André et al. (2017, p. 516), "as professoras iniciantes precisam ouvir uma profissional mais experiente que lhes dê atenção não apenas em relação ao aspecto didático, mas afetivo também." Estas egressas da licenciatura tiveram poucas experiências de práticas em curtos estágios durante a formação inicial, portanto têm pouco domínio sobre práticas pedagógicas. Então, "necessitam de alguém que as ajude a refletir sobre sua prática". Acompanhando este processo passo a passo durante sua formação, há os graduandos que desenvolvem estudos, observam, ouvem atentamente as experiências da/na formação e nesse processo inserem suas indagações de pesquisa de seus Trabalhos de Conclusão de Curso e também os mestrandos que acompanham as atividades, auxiliam na preparação das reuniões de formação e nesse processo vão também, descortinando seus temas de pesquisa. Assim, estudos, formação e pesquisa se articulam no projeto OBEDUC/ UFMT junto às redes de ensino e universidade.

Neste sentido, o presente artigo trata do projeto OBEDUC/UFMT desenvolvido junto ao Programa de PósGraduação em Educação de Rondonópolis com o intuito de abordar sua estrutura bem como a natureza dos trabalhos desenvolvidos em dimensões da formação de professores. Os instrumentos adotados para as pesquisas desenvolvidas com o OBEDUC centram-se nas narrativas. Geralmente, são constituídos por diários de campo reflexivos, os memoriais de formação e as entrevistas-narrativas. Apresentam-se, ao final de cada parte deste texto, alguns excertos resultantes de pesquisas já desenvolvidas sobre o tema em que as narrativas dos sujeitos evidenciam sua evolução no projeto.

\section{O OBEDUC/UFMT E AS DIMENSÕES DA FORMAÇÃO EM REDES DE COLABORAÇÃO QUE SUSTENTAM AS PESQUISAS}

A formação continuada desenvolvida pelo projeto é organizada por um coordenador e um professor do Programa de Pós-Graduação em Educação/PPGEdu/UFMT, contando com o auxílio de seis professores da escola básica, quatro mestrandos, seis coordenadores e 36 professores iniciantes, somando, até 2016, o total de 51 participantes.

\section{AS TRÊS DIMENSÕES DA FORMAÇÃO NO PROJETO OBEDUC}

A formação continuada se dá em três dimensões, que seguem abaixo descritas, uma com os graduandos, outra com os professores iniciantes e a terceira com os professores da escola básica (denominados no projeto de professores experientes). Em todas elas, os participantes sinalizam a pauta de sua formação.

\section{A) A DIMENSÃO DA FORMAÇÃO COM OS GRADUANDOS}

Denominada como estudos adicionais à formação inicial, deenvolve-se semanalmente em três turnos de estudos: em um contraturno da graduação em Pedagogia, os graduandos leem os textos e discutem entre seus pares; Em outro, há uma discussão coletiva de suas reflexões com a coordenadora do projeto, com 


\section{DOCENTE}

autêntica

as mestrandas e professores da rede pública, estes últimos, voluntariamente, participam dos estudos. Um outro encontro ainda acontece à noite, quinzenalmente, quando os graduandos somam-se aos professores iniciantes, aos professores experientes da escola básica, a mestrandos, gestores e equipe do projeto, para a formação coletiva.

Os textos selecionados para o estudo passam pelo questionamento dos professores do projeto OBEDUC/ UFMT, junto aos demais colegas docentes do curso de Pedagogia, no intuito de identificar autores já estudados nas disciplinas, de modo que os mesmos-não se repitam nos estudos adicionais. Dessa forma, é possibilitado o acesso a outros teóricos, ampliando as reflexões.

Questiona-se também junto aos professores das disciplinas, por meio de entrevista informal, se percebem alguma diferença no que tange às discussões dos estudantes do OBEDUC nos conteúdos abordados em sala e nos trabalhos produzidos, de modo a configurar se há uma participação com maiores contribuições com outros referenciais por parte dos graduandos do OBEDUC. Respostas já evidenciaram positivamente à participação e contribuições dos alunos, dado este que incita outros colegas a participarem dos estudos. Destes encontros, surgem inquietações que mobilizam as questões das pesquisas dos Trabalhos de Conclusão de Curso dos graduandos de Pedagogia. Os temas, então, giram em torno do projeto colaborativo do OBEDUC, sinalizando pesquisas com os participantes do OBEDUC.

A importância de projetos colaborativos na formação de professores é ressaltada por Imbernón (2009, p. 71) ao afirmar que, "se o professorado não impulsionar uma nova cultura colaborativa nas instituições educativas, [...] será impossível por sua vez desenvolver processos de formação permanente, colaborativos e uma inovação institucional." É relevante salientar que os projetos colaborativos têm o potencial de fluidificar relações de docência em diferentes níveis (Universidade-escolas), fomentando estudos sobre a prática, a partir dos diferentes loci, além de alavancar reflexões em torno da formação inicial e continuada. Passos (2016, p. 171) observa que "cada grupo tem características particulares que o move, tem uma história. As experiências e vivências trazidas pelos integrantes vão, de certo modo, caracterizando esse grupo e construindo sua história".

Ainda neste percurso, os graduandos produzem textos junto aos mestrandos, professores da escola básica e coordenadora do projeto, apresentando-os em eventos. Observa-se, então que as redes de estudos entre os graduandos, escola e pós-graduação se efetivam nesta dimensão da formação. Assim, neste percurso de estudos e pesquisa, os graduandos vão perfazendo um dos objetivos do OBEDUC, que é o de "incentivar a articulação entre pós-graduação, licenciaturas e escolas de educação básica".

Os estudos vêm se desenvolvendo desde o ano de 2013 e, neste artigo, é apresentado um recorte dos temas estudados em 2016, os trabalhos produzidos em eventos e as pesquisas de TCC dos graduandos sobre o tema. Isto se dá no intuito de caracterizar que os estudos e pesquisas acontecem em redes, como se pode observar a seguir. 


\section{autêntica}

QUADRO 1- ESTUDOS E REFLEXÕES COM OS GRADUANDOS NO ANO DE 2016.

\begin{tabular}{|c|c|}
\hline TEMA & MEDIADOR \\
\hline O curso de licenciatura em Pedagogia & $\begin{array}{l}\text { Bernadete Gatti } \\
\text { Relatório de pesquisa } 2009\end{array}$ \\
\hline $\begin{array}{l}\text { Licenciatura em Pedagogia: o que narram os } \\
\text { egressos - professores iniciantes acerca dos } \\
\text { caminhos e descaminhos na/da prática docente. }\end{array}$ & $\begin{array}{c}\text { Texto resultado de evento-pesquisa de } \\
\text { graduandas, com egressa e coordenadora do } \\
\text { OBEDUC } \\
\text { Carolini Rodrigues Groto Souza } \\
\text { Elaine Borges Rodrigues } \\
\text { Maria Pina de Souza Santana } \\
\text { Simone Albuquerque da Rocha }\end{array}$ \\
\hline $\begin{array}{l}\text { As diferentes nomenclaturas atribuídas aos profes- } \\
\text { sores experientes; }\end{array}$ & $\begin{array}{l}\text { Pesquisa de Sueli Oliveira de Souza -mestrado } \\
\text { OBEDUC }\end{array}$ \\
\hline Os professores diante do saber. & Maurice Tardif \\
\hline A formação do professor & Antonio Nóvoa \\
\hline Elementos para uma teoria da prática educativa. & Imbernon \\
\hline $\begin{array}{l}\text { O professor enquanto "ator racional"- Que racionali- } \\
\text { dade, que saber, que juízo? }\end{array}$ & Maurice Tardif \\
\hline Formação de professores e profissão docente. & Antônio Nóvoa \\
\hline Profissionalização e formação de professores; & Thomas S. Popkewitz \\
\hline A formação de professores: novas perspectivas. & Carlos Marcelo \\
\hline Formar professores como profissionais reflexivos. & Donald Schon \\
\hline O que é ser professor? & $\begin{array}{l}\text { Denise da Silva Braga } \\
\text { Gislene Valério de Barros }\end{array}$ \\
\hline
\end{tabular}

Fonte: Rocha, 2017.

A seguir registram-se as pesquisas que tiveram sua origem nos estudos em rede envolvendo escolas, pós-graduação e graduação. São os TCC's das graduandas em Pedagogia gestados a partir das relações com o outro e das indagações que vão surgindo no percurso da formação coletiva articulados ao projeto OBEDUC/ UFMT. O egresso da Pedagogia da UFMT- professor iniciante e sua participação nas práticas coletivas de formação continuada na escola: um estudo investigativo. Autora-Anastácia Aparecida Trindade/2015

- Os egressos da Pedagogia da Universidade Federal de Mato Grosso e seus dilemas frente ao planejamento das atividades na educação infantil na perspectiva interdisciplinar. Autora-graduanda: Maria Pina de Souza Santana/2015

- Professores iniciantes/egressos da Pedagogia: desafios da prática interdisciplinar no $5^{\circ}$ ano do ensino fundamental de escolas públicas de Rondonópolis-MT. Autora-graduanda: Noemia Madureira de Souza/2015 
- Professor iniciante e a trilha de estudante a professor. Autora-graduanda: Jessica Lorrayne Ananias/2016

- Formação de professores: o professor iniciante e o uso das tecnologias a partir do projeto OBEDUC/ PPGEDU/UFMT. Autora-graduanda: Izabel Delgado da Silva Matos/2016

- O OBEDUC e a formação do professor experiente: o que narram os iniciantes sobre o processo de acompanhamento?. Autora-graduanda: Rosinéia Teixeira Ribeiro/2016

- O professor iniciante alfabetizador: o que revelam suas narrativas sobre a travessia de estudante a professor?

- Autora-graduanda: Elaine Borges Rodrigues/2017

Como se pode observar, o projeto do OBEDUC desenvolve sua rede de pesquisas e estudos com os graduandos a partir do projeto de origem. As produções de textos em articulações com graduandos, professor iniciante, mestrandos e coordenadora do programa somaram 13 publicações em três anos, participação em 8 eventos de pesquisa, o que evidencia um envolvimento interessante dos graduandos em seus estudos, no relacionamento com os mestrandos e coordenadora do OBEDUC.

O que revelam os graduandos sobre os estudos no OBEDUC? A pesquisa das smestrandas Cardoso, Silva e Souza (2017) que investiga sobre graduandos em grupos colaborativos de pesquisa e suas interações/ produções: algumas possibilidades, apontou detalhes interessantes na coleta de dados, a seguir descritos em dois recortes:

Os estudos do OBEDUC, enquanto graduanda em formação, possibilitam tomar nota de conhecimentos que os estudos da própria academia não dão conta. Assim, me deparando com essas leituras, com esses autores, Tardif, Nóvoa, Imbernón, com esses autores mesmo dos nossos estudos que nós temos semanais, têm contribuído para me constituir professora. [...] Significa pra minha reflexão, os estudos são uma formação que vão para além das possibilidades, assim, olhar que tudo é possível, que se você acreditar, é possível você fazer a educação diferente, é possível agir diferente, se você quiser, se você parar para refletir, existem outras formas de agir, de se educar, além do tradicional [...] (Entrevista, Rosa, 2016. In: CARDOSO; SILVA; SOUZA 2016, p11).

[...] Na minha construção como professora, eu vejo que estes estudos contribuem para que eu tenha uma formação reflexiva [...] como sendo uma professora reflexiva com a realidade de cada aluno, e também, assim, parar um pouco antes de tomar certas decisões, sempre, para estar ouvindo primeiro as crianças ou adultos [...] para começar a construir a proposta pedagógica, porque ela não deve partir só de mim, ela deve partir também de uma construção do educando (Entrevista, Violeta, 2016. In: CARDOSO; SILVA; SOUZA 2016, p.10).

\section{B) A DIMENSÃO DA FORMAÇÃO COM OS PROFESSORES INICIANTES NO PROJETO OBEDUC/ UFMT EM REDES DE FORMAÇÃO}

O projeto iniciou suas atividades mapeando as escolas onde se situam os professores iniciantes nas redes de ensino, tomando como perfil aqueles que tinham até cinco anos de docência. Feito isto, foram convidadas seis escolas que detinham maior número de iniciantes para entrarem no projeto, havendo uma palestra da 


\section{autêntica}

coordenação em cada escola, junto à gestão e aos professores, para delineamento dos detalhes do desenvolvimento do projeto.

A seguir, a equipe do projeto reuniu-se com as escolas, os professores-coordenadores e os professores iniciantes para que estes últimos manifestassem suas dificuldades e desafios nesta fase da docência, bem como as necessidades formativas de que precisavam. Para Tardif (2014), o professor iniciante é aquele profissional que tem até cinco anos de magistério, que se depara com uma série de dilemas ao estrear na profissão e a quem são atribuídas turmas difíceis, além de horários que os outros professores descartaram de aceitar, sofrendo, ainda, com a falta de compreensão e de auxílio dos colegas. Tardif (2014, p. 87) assevera que isso contribui para que sofram um "choque com a realidade", no qual evidenciam a compreensão não somente de sua competência, mas de seu ambiente de trabalho.

Da mesma forma, Gabardo e Hobold (2011, p. 85) compreendem que "este é um período marcado por sentimentos contraditórios que desafiam cotidianamente o professor e sua prática docente". Assim, a partir do diagnóstico das dificuldades e necessidades dos iniciantes, inicia-se a formação continuada do projeto OBEDUC/UFMT cuja autoria é competência dos professores egressos. Isto quer dizer que eles organizam a agenda de sua formação em reuniões coletivas, sugerem como pretendem que esta aconteça, porém, sempre ouvindo as propostas da equipe/OBEDUC e os diálogos necessários à compreensão do que se refere a necessidades, desejos, vontades e especulações.

Para o atendimento às reivindicações dos egressos em formação, a coordenação e equipe do projeto busca os formadores nas parcerias com a Semed e Seduc, além do programa de Pós-Graduação/PPGEdu/UFMT. Ressalta Nacarato (2016, p. 713) que esse processo " [...] demanda respeito pelo trabalho do outro: os professores acadêmicos precisam colocar-se à escuta dos professores da escola básica e trabalhar na perspectiva de que o que estes têm a dizer tem importância e precisa ser o ponto de partida para um trabalho coletivo". Argumenta a autora que "os professores da escola básica, por sua vez, à medida que sentem confiança nos formadores, aderem à proposta de trabalho coletivo. Assim, a parceria potencializa aprendizagens recíprocas".

De acordo com Day (2001, p.213), a formação contínua deve considerar "as fases de desenvolvimento dos professores, os seus propósitos morais centrais e as suas necessidades de desenvolvimento intelectual e emocional [...]"; se isso não acontecer, "pouco poderá contribuir para o desenvolvimento profissional docente".

Carlos Marcelo (2010, p. 18) comenta que o início da profissão docente é "um período de tempo que abarca os primeiros anos, nos quais os professores realizam a transição de estudantes para docentes." Segundo Vaillant e Marcelo (2012), a inserção à docência é um período tenso, marcado por aprendizagens centradas em um contexto desconhecido, no qual os professores iniciantes devem adquirir conhecimento profissional. Trata-se, então, de uma etapa decisiva para a permanência na profissão ou para sua desistência, sendo considerada, por Mira e Romanowski (2014), como uma das importantes fases do desenvolvimento profissional do professor.

Assim, o ritual de transição de aluno a professor ocorre em um período crítico pelo qual todos os docentes passam, mas poucos o rememoram, salvo quando são solicitados a falarem sobre a inserção na docência. Esse período, então, que é inerente à profissão do professor, tem sido silenciado e raramente discutido e/ ou partilhado em discussões e pesquisas, havendo na atualidade uma retomada à questão por alguns pesquisadores que vêm trazendo estes temas para o debate. Conforme apontam Andre et al. (2017, p.506), "esses professores iniciantes, egressos dos cursos de formação, sem o apoio da academia, experimentam a condição de 'órfãos' no espaço escolar no qual estão inseridos". 
No Brasil, Gatti, Barreto e André (2011) evidenciam que, de 15 estados pesquisados dentre os 26 existentes, apenas três apresentam políticas de inserção à docência, o que se torna insignificante considerando-se a amplitude do contexto nacional.

\section{A AUTORIA DA FORMAÇÃO PELOS INICIANTES NO OBEDUC/UFMT: DELINEANDO O PROCESSO}

A formação do professor iniciante no projeto colaborativo entre universidade e escolas da educação básica OBEDUC é realizada em encontros quinzenais que acontecem na forma de reuniões expositivo-dialogadas; formação seguida de oficina; formação seguida de projetos na prática docente com discussões no coletivo sobre seus resultados; estudos sobre novas legislações que atingem a carreira docente; políticas educacionais, entre outras atividades. As reuniões são desenvolvidas com o acompanhamento da gestão da escola - o coordenador pedagógico e outro membro da gestão. Isto porque o iniciante é ainda pouco reconhecido e inexperiente em seu trabalho e contar com o apoio de quem o acompanha também na formação, facilita a inserção de novas práticas advindas dos estudos. Afirmam André et al. (2017, p. 514) que, para algumas professoras iniciantes, "enfrentar os desafios que a prática lhes coloca tem sido um trabalho solitário, pois raramente contam com algum tipo de ajuda, o que pode trazer sentimentos de desânimo, de insatisfação".

Tais reuniões de formação acontecem de forma itinerante, na universidade e nas seis escolas que participam do projeto. Tomou-se esta iniciativa com base na solicitação dos iniciantes de que deveriam conhecer o espaço da docência dos seus pares para compreenderem melhor suas relações na formação em curso. A itinerância fortalece as relações entre os professores, compartilha práticas, ambientes, projetos e espaços, além de socializar aos pares os espaços de ensinar e aprender.

No que diz respeito ao espaço/tempo do desenvolvimento dos temas da formação, estes também são decididos pelos egressos. É interessante ressaltar que, em muitos casos, o ritmo e a ordem da formação continuada por eles demarcada no início do semestre são interrompidos por uma emergência surgida durante suas práticas. Este fato consiste em constante preocupação da coordenação, posto que o contingente de iniciantes se renova, por apresentar alto índice de mobilidade, de modo que torna-se necessário repensar o processo de formação e os temas a serem trabalhados. Geralmente, essas emergências emanam de solicitações da Semed ou Seduc na cobrança de novas atividades até então desconhecidas pelos novos professores e nunca vivenciadas na formação inicial. Entre algumas delas, podem ser citadas: a avaliação diagnóstica na entrada do ano letivo, os relatórios bimestrais e semestrais de avaliação dos alunos, diários on-line, atividades com descritores de aprendizagem como forma de alavancar o Índice de Desenvolvimento da Escola Básica (IDEB) das escolas, dentre outras. Tais ocorrências requerem da coordenação do projeto buscar alternativas, também emergenciais, normalmente nos setores de cobrança - Semed e Seduc -, por meio dos seus Centros de Formação e atualização dos profissionais da educação (CEFAPRO's), os quais, prontamente, comparecem à Universidade para os encontros de orientação.

Dessa maneira, a formação, quando propiciada pelos mesmos organismos que determinam as cobranças de atividades, então desconhecidas pelos professores iniciantes, resulta em maiores aprendizagens e construção de conhecimentos, evitando-se equívocos e desperdício de tempo para a aquisição de determinados conhecimentos ainda não assimilados Assim, redes de discussões entre universidade, município e estado estão constantemente sendo acionadas e se somam à formação do professor iniciante em Rondonópolis/ MT. Nesse sentido, a formação pode acontecer "como uma aprendizagem que deve se dar por meio de situações práticas que sejam efetivamente problemáticas, o que exige o desenvolvimento de uma prática reflexiva competente." (MIZUKAMI et al., 2002, p. 12). 


\section{autêntica}

Acerca dessa proposta de autoria da formação de professores pelos próprios participantes em projetos que articulam universidade/escolas, o do OBEDUC/UFMT tem se evidenciado propositivo ao desenvolvimento da prática reflexiva. Outro fator que promove a autoria é o sentimento de pertença do grupo, manifestado por meio de desejos, propostas, dificuldades e necessidades a partir de um espaço/tempo comum aliado a importante componente, o da liberdade e aceitação da equipe da gestão do OBEDUC/UFMT. Sobre isso, a coordenação atendeu ao pedido da gestão de duas escolas do campo que solicitaram sua inserção junto aos seus pares - professores iniciantes, na formação do OBEDUC. O pedido se justificava com base no desejo da inclusão do campo nos estudos de formação, uma vez que os docentes se sentiam excluídos de políticas de formação continuada em seu espaço. Havendo sido inseridos no projeto, este fato tornou a formação continuada uma proposta ímpar, ao associar pares de diferentes realidades nas discussões sobre a formação. A agenda de formação sofreu alterações com a inclusão desse grupo e, coletiva e consensualmente, ela foi reestruturada.

Para dinamizar a comunicação em um grupo com vivências e práticas diferenciadas e ricas nas discussões, a gestão criou um espaço de diálogo entre os participantes, com grupos de WhatsApp e uma página no Facebook/OBEDUC/UFMT, que s pode ser utilizada para solicitação, registro e manifestação de opinião sobre a formação continuada ou eventos do OBEDUC/UFMT. Toda a reunião é gravada em áudio, documentada em fotos, sendo que as mensagens dos participantes no WhatsApp são registradas na forma de print e arquivadas como documentos de pesquisa.

Isto posto, o que manifestam os professores em sua autoria de estudos? Apresenta-se, a seguir, um recorte da agenda de 2016, tendo em vista que o projeto avança para o quarto ano de atividades e inserir todos os anos ficaria muito extensa a produção textual.

\section{QUADRO 2 - TEMAS ABORDADOS NA FORMAÇÃO DO PROFESSOR INICIANTE NO ANO DE 2016}

\begin{tabular}{|c|c|}
\hline TEMA & MEDIADOR \\
\hline Retrospectiva Formação 2015 & $\begin{array}{c}\text { Professoras da equipe do PPGEdu e } \\
\text { mestrandas do PPGEdu }\end{array}$ \\
\hline Descritores e matriz de referência & $\begin{array}{c}\text { Professora do CEFAPRO/Seduc - } \\
\text { Rondonópolis/MT }\end{array}$ \\
\hline $\begin{array}{l}\text { Psicologia, educação e as temáticas da vida con- } \\
\text { temporânea - dificuldades de aprendizagem de } \\
\text { alunos }\end{array}$ & Prof. Dr. em Psicologia do PPGEdu/UFMT \\
\hline Dificuldades de Aprendizagem & Profa. da equipe do projeto \\
\hline Constituição da Identidade Docente & Prof. Do PPGEdu/UFMT \\
\hline A sexualidade na Educação Infantil & $\begin{array}{l}\text { Prof. Dra. em Psicologia infantil do PPGEdu/ } \\
\text { UFMT }\end{array}$ \\
\hline Elaboração de relatórios descritivos & $\begin{array}{l}\text { Profa. Mestranda Sueli Oliveira de Souza da } \\
\text { Semed e PPGEdu/UFMT }\end{array}$ \\
\hline Base Nacional Comum Curricular (BNCC) & $\begin{array}{l}\text { Profa. Dra. Em Currículo do } \\
\text { PPGEdu/UFMT }\end{array}$ \\
\hline
\end{tabular}




\begin{tabular}{|c|c|}
\hline $\begin{array}{c}\text { Fases de desenvolvimento no processo } \\
\text { de aprendizagem da escrita }\end{array}$ & $\begin{array}{c}\text { Profa. Dra. Em Alfabetização e coordenadora } \\
\text { do Pacto- PPGEdu/UFMT }\end{array}$ \\
\hline $\begin{array}{c}\text { Seminário OBEDUC 2016 e XXI Encontro } \\
\text { de Pedagogia }\end{array}$ & $\begin{array}{c}\text { Mesa de discussão sobre as dificuldades } \\
\text { dos iniciantes - diálogos } \\
\text { Mesa de discussão sobre as práticas } \\
\text { na Educação do Campo- diálogos }\end{array}$ \\
\hline $\begin{array}{c}\text { Políticas Educacionais } \\
\text { PEC, Escola sem partido }\end{array}$ & $\begin{array}{c}\text { Profa. Dra. Líder sindical dos docentes } \\
\text { do PPGEdu/UFMT }\end{array}$ \\
\hline $\begin{array}{c}\text { Fases de desenvolvimento no processo de } \\
\text { aprendizagem }\end{array}$ & $\begin{array}{c}\text { Profas. Mestrandas Sueli Oliveira de Souza e } \\
\text { Profa. Elizabete Gaspar. PPGEdu/Semed }\end{array}$ \\
\hline $\begin{array}{c}\text { Formação de professores e inclusão do aluno } \\
\text { com deficiência no ensino-aprendizagem }\end{array}$ & $\begin{array}{c}\text { Profa. Dra. Jacirene Lima Pires dos Santos / } \\
\text { Semed }\end{array}$ \\
\hline $\begin{array}{c}\text { trabalho colaborativo aproximação universidade/ } \\
\text { escola }\end{array}$ & $\begin{array}{c}\text { Profa. Do PPGEdu/UFMT } \\
\text { Formação Escolas do Campo }\end{array}$ \\
\hline $\begin{array}{c}\text { Equipe do projeto OBEDUC e líderes do MST } \\
\text { e Educação do Campo. }\end{array}$ \\
\hline
\end{tabular}

Fonte: Lorenzzon, 2017, p. 69, adaptada por Rocha.

A autoria da formação solicitada pelos professores iniciantes foi atendida pela equipe do projeto, que manteve redes de relações com a Semed, Seduc e PPGEdu, de modo a atingir os interesses do grupo. No entanto, a ordem e o ritmo dos temas nem sempre foi seguida, o que se deveu aos interesses que surgiram no percurso, às medidas emergenciais de cobranças advindas dos sistemas e ao inusitado com que se depararam os iniciantes em suas práticas, precisando então dialogar com seus pares.

Um caso de pausa da programação para privilegiar um tema não listado pelos iniciantes que pode ser citado como exemplo refere-se a quando um professor iniciante da educação do campo assim ressaltou: "colegas professores, não sabemos como fazer, estamos com um problema nunca visto ainda em nossas práticas e não sabemos como lidar com isso, precisamos de ajuda". Ficaram todos apreensivos quando, então, em meio à reunião coletiva disseram: "a sexualidade na Educação Infantil chegou ao campo e não sabemos como lidar com isso". Afirmaram que: "são filhos de sitiantes nossos vizinhos e como iremos falar com eles?" Em decorrência dessa discussão, apontaram a necessidade de haver uma formação nesse sentido, para dar acesso a um tema de caráter emergencial, pois estavam muito aflitos.

A partir desse pedido, outras escolas manifestaram-se sobre a urgência em discutir este mesmo tema. Diante disso, interrompeu-se o cronograma e solicitou-se a colaboração a uma psicóloga da infância do PPGEdu, que procedeu à formação. Foram solicitados e necessários três encontros para amenizarem as tensões e discussões dos textos indicados para a compreensão desta fase na infância. Participou das discussões um orientando da professora psicóloga, o qual compareceu a todas as escolas e continuou a formação no horário da Hora de Trabalho Pedagógico Coletivo (HTPC) com os professores. Suas ações nessas atividades instigaram a elaboração de um projeto de pesquisa de mestrado. Depreende-se, assim, que um tema pouco Łangido mas que perpassa naturalmente a infância, consistiu em um desafio para os professores, instigando 


\section{autêntica}

uma questão para uma pesquisa em nível de pós-graduação. Das redes de relações para a pesquisa, esta tem disse sido uma possibilidade frequente no projeto OBEDUC/UFMT.

No projeto colaborativo, portanto, é possível socializar e solicitar auxílio via formação. Nesse sentido, Reali, Tancredi e Mizukami (2008) apontam que, na cultura colaborativa, docentes experientes e iniciantes trabaIham em conjunto e trocam ideias sobre problemáticas reais e colocam sua base de conhecimento comum em ação, vivenciando relações recíprocas entre teoria e prática. Já autores como Nono e Mizukami (2006) enfatizam a importância do compartilhamento de conhecimentos entre professores, relatando que esse tipo de trabalho contribui na solução de dilemas e auxilia nas deliberações.

Este período de inserção do professor na profissão e na carreira requer um acompanhamento, diante dos problemas de relacionamento inicial em um espaço desconhecido e uma profissão ainda não vivenciada. André et al. (2017, p. 515) discorrem sobre o papel do outro no acompanhamento ao iniciante ao afirmarem que o apoio aos iniciantes é fundamental assim como as condições de trabalho e a possibilidade de trabaIhos junto aos demais professores da escola. Some-se a isso a inserção na escola e o "acolhimento ao seu estado emocional, pela aceitação e reconhecimento de suas fragilidades advindas da pouca experiência. Afirmam as autoras que, diante disso, há "a necessidade do outro, ou seja, o coordenador pedagógico, para dar continuidade ao processo formativo do professor iniciante".

Para Hubermann (2013), o professor iniciante é o novo profissional que está na fase nebulosa da profissão, para o qual nada está muito claro, desconhece o dia a dia da prática, consistindo em um período de "sobrevivência", de "choque do real", precisando, assim, de apoio, acolhimento, acompanhamento. Questiona-se, então, de que tipo de acompanhamento necessita o iniciante? Que atividades devem compor o acompanhamento? Que possibilidades de compartilhamento de saberes podem surgir nesse processo?

O próximo quadro registra recortes de pesquisas de mestrandos sobre o desenvolvimento profissional de professores iniciantes, a formação do iniciante para o uso das mídias e interações na prática educativa, o iniciante e a educação do campo, o relacionamento iniciante-escola, entre outras produções.-

Quadro 3 - Pesquisas desenvolvidas em nível stricto sensu envolvendo o tema do projeto OBEDUC/UFMT - iniciantes e experientes em desenvolvimento profissional

\begin{tabular}{|c|c|c|}
\hline AUTORES & TíTULOS DAS DISSERTAÇÕES & ANO \\
\hline $\begin{array}{c}\text { Solange Lemes da Silva } \\
\text { Mendes }\end{array}$ & $\begin{array}{c}\text { Políticas de formação continuada em Mato Grosso } \\
\text { sob o olhar de professores iniciantes }\end{array}$ & 2014 \\
\hline Suely Maria Pires & $\begin{array}{c}\text { Políticas de formação e trabalho docente: narrativas de } \\
\text { professores da escola do campo }\end{array}$ & 2014 \\
\hline Rozilene de Morais Sousa & $\begin{array}{c}\text { Professores iniciantes e professores experientes: } \\
\text { articulações possíveis para a formação e inserção } \\
\text { na docência }\end{array}$ & 2015 \\
\hline Ivete Cevallos PNPD & $\begin{array}{c}\text { O assessoramento do professor da educação básica } \\
\text { em processo de inserção profissional: possibilidades e } \\
\text { desafios }\end{array}$ & 2015 \\
\hline
\end{tabular}




\begin{tabular}{|c|c|c|}
\hline $\begin{array}{c}\text { Márcia Socorro dos Santos } \\
\text { França }\end{array}$ & $\begin{array}{c}\text { O desenvolvimento profissional dos professores iniciantes } \\
\text { egressos do curso de licenciatura em Pedagogia: um } \\
\text { estudo de caso }\end{array}$ & 2016 \\
\hline Liziane Mello Wesz & $\begin{array}{c}\text { Os professores iniciantes e o uso das mídias digitais nas } \\
\text { práticas educativas }\end{array}$ & 2016 \\
\hline Sueli Souza & $\begin{array}{c}\text { O desenvolvimento profissional do professor experiente } \\
\text { no projeto colaborativo universidade - escola: dilemas e } \\
\text { desafios }\end{array}$ & 2017 \\
\hline Márcia Lorenzzon & $\begin{array}{l}\text { Narrativas dialogadas nos diários de campo reflexivos de } \\
\text { professoras iniciantes: possibilidades de autoformação }\end{array}$ & 2017 \\
\hline Oldair José Tavares & $\begin{array}{l}\text { O professor iniciante da escola do campo e sua formação - } \\
\text { por entre espelhos... }\end{array}$ & 2017 \\
\hline \multicolumn{3}{|l|}{$\begin{array}{l}\text { PESQUISAS EM } \\
\text { ANDAMENTO }\end{array}$} \\
\hline Adriane Silva & O professor iniciante e o abandono da docência & 2017 \\
\hline Fernanda Cardoso & $\begin{array}{l}\text { Licenciandos em grupos de pesquisa: percepções, } \\
\text { constatações e envolvimento na formação docente. }\end{array}$ & 2017 \\
\hline Elizabete Gaspar & $\begin{array}{l}\text { O coordenador pedagógico e sua inserção no OBEDUC: } \\
\text { trajetórias e travessias na formação de professores na } \\
\text { escola }\end{array}$ & 2017 \\
\hline Dulcilene Rodrigues Souza & $\begin{array}{c}\text { A itinerância no OBEDUC: as interações em diferentes } \\
\text { espaços e práticas nas/das escolas públicas com o } \\
\text { OBEDUC/UFMT }\end{array}$ & 2017 \\
\hline
\end{tabular}

Fonte: Rocha, 2017

\section{C) A DIMENSÃO DA FORMAÇÃO DO PROFESSOR DA ESCOLA BÁSICA (PROFESSOR EXPERIENTE) NO PROJETO OBEDUC/UFMT - AS REDES ENVOLVIDAS}

O programa OBEDUC prevê, em sua estrutura de projetos aprovados, a inclusão de professores da escola básica. No caso deste projeto da UFMT, há seis professores que atuam como apoio, suporte, orientação aos professores em início de carreira em suas escolas, devendo estes participarem das reuniões coletivas quinzenais com os iniciantes de sua escola acompanhado de um gestor, de modo que possam compreender as dificuldades dos novos professores, acompanhá-los e apoiá-los no investimento de alguma ação advinda da formação. Destaca-se, desse modo, a importância do acompanhamento do professor com mais experiência, então denominado no OBEDUC/UFMT de professor experiente, na trajetória de formação continuada coletiva e itinerante. Geralmente este professor experiente, com maior tempo para o atendimento ao iniciante neste projeto, tem sido o coordenador/supervisor pedagógico da escola. 
A inserção desse profissional previsto pelo projeto OBEDUC/UFMT resultou em importante contribuição ao iniciante, posto que pôde nele se referenciar sentindo-se melhor amparado. Desde a instituição deste profissional no processo de acompanhamento ao iniciante, inclusive nas reuniões de formação do OBEDUC/ UFMT, foi possível compreender melhor o perfil do iniciante, bem como disseminar, na escola, a prática do acolhimento, do apoio e da inclusão ao grupo de docentes. Há a afirmação nas falas dos professores da educação básica onde se desenvolve o projeto de que, "antes do OBEDUC, a escola nem percebia o iniciante e depois do Obeduc, tiramos as viseiras".

O acompanhamento ao iniciante é feito nos momentos em que ele procura o experiente e na Hora de Trabalho Pedagógico Coletivo (HTPC), quando, então, é destinado um espaço aos novatos para discutirem sobre suas práticas. Este espaço só Ihes foi delegado depois de a escola entrar no projeto.

Para o exercício da função de acompanhamento, houve estudos, leitura das necessidades dos iniciantes, estruturando-se o plano de ação dos experientes. Passado um ano no exercício da função, houve uma reunião com os experientes quando estes solicitaram formação, justificando que suas atividades de coordenação na escola sempre foram voltadas para o cotidiano, a formação de professores, a organização do trabalho pedagógico, entre outros e que esta nova função estava a desafiá-los com novas atividades de acompanhamento e de formação, que não as já desenvolvidas como formadores de formadores. Tratava-se de um trabalho de experientes, desenvolvido por iniciantes, diziam eles.

Assim, respeitando mais uma vez a autoria, possibilitou-se aos experientes a organização de sua agenda de formação. Entre os estudos, constava a necessidade de compreensão sobre a função de acompanhar, então totalmente em outra dimensão das já praticadas como coordenadores pedagógicos para um corpo de professores com tempo de prática, posto que aos iniciantes era requerido outro tipo de postura, de atenção e de trabalho de formação na escola. Os temas selecionados para a formação do experiente focavam a dimensão do processo de acompanhar o iniciante, a formação do formador, exigências para o processo de acompanhar novos professores, perfil e atividades inerentes à função.

Assim, com base na agenda por eles organizada, registram-se, no Quadro 4, a seguir, os estudos de 2016 com os professores experientes (coordenadores das escolas públicas).

QUADRO 4 - AGENDA DA FORMAÇÃO DOS PROFESSORES EXPERIENTES 2016

\begin{tabular}{|c|c|}
\hline TEMA & MEDIADOR \\
\hline $\begin{array}{c}\text { Avaliação do trabalho do experiente junto ao iniciante } \\
\text { ano } 2015 \text { e elaboração da pauta de trabalho para 2016 }\end{array}$ & Professora do PPGEdu/UFMT \\
\hline Formação do formador & Tese de doutorado PUC-SP \\
\hline Constituição da identidade & Autora da pesquisa \\
\hline Aprendizagem da docência - texto da Mizukami 2005 & Professora do PPGEdu \\
\hline
\end{tabular}




\begin{tabular}{|c|c|}
\hline $\begin{array}{l}\text { Alguns programas de acompanhamento - texto } \\
\qquad \text { Ochoa (2011) } \\
\text { O início do acompanhamento no programa UFMT/ } \\
\text { OBEDUC, texto: Sousa (2015). }\end{array}$ & Professoras Experientes: \\
\hline $\begin{array}{c}\text { Diferentes programas de monitoria. Torres, Ochoa } \\
\text { (2010). Formação docente para novos cenários - } \\
\text { Meana G. Dora (2010) }\end{array}$ & Mestranda \\
\hline Desenvolvimento profissional do professor; & Exposição da Dissertação de mestranda \\
\hline $\begin{array}{l}\text { O professor experiente na óptica de diferentes } \\
\text { autores; }\end{array}$ & Profa do PPGEdu e uma mestranda \\
\hline $\begin{array}{c}\text { Narrativas dialogadas - técnica de autoscopia } \\
\text {-Propostas de intervenção-formação dos professores } \\
\text { experientes }\end{array}$ & $\begin{array}{l}\text { Professores e mestrandos da equipe do } \\
\text { projeto. } \\
\text { Professores experientes. }\end{array}$ \\
\hline $\begin{array}{c}\text { Narrativas dialogadas e Discussão de aulas gravadas } \\
\text { para possíveis intervenções. }\end{array}$ & $\begin{array}{l}\text { Professora PPGEdu/UFMT } \\
\text { Professoras experientes }\end{array}$ \\
\hline $\begin{array}{l}\text { Organização do seminário OBEDUC, Discussão de } \\
\text { aulas gravadas para possíveis intervenções. }\end{array}$ & Professoras do PPGEdu/UFMT \\
\hline $\begin{array}{c}\text { Melhorar a escrita de relatórios e o relato da profes- } \\
\text { sora coordenadora sobre sua participação no GT8 } \\
\text { grupo da ANPED }\end{array}$ & Professora do PPGEdu e mestrandas \\
\hline $\begin{array}{c}\text { Avaliação do trabalho do experiente e iniciante ano } \\
2016 \text { e elaboração da pauta 2017, programação da } \\
\text { visita às escolas do campo }\end{array}$ & Professora do PPGEdu e mestrandas \\
\hline
\end{tabular}

Fonte: Souza, 2017.

Os estudos com os professores experientes propiciaram grandes contribuições, advindas das atividades de estudar, discutir, para depois compreender a dimensão da função de acompanhamento. Redes de estudos apoiados em pesquisas de doutorado recentemente defendidas em diferentes Instituições de Ensino Superior (IES) como Universidade Estadual de Mato Grosso (UNEMAT), Pontifícia Universidade Católica de São Paulo (PUC-SP), Universidade Federal de Santa Catarina (UFSC), Universidade Federal do Rio Grande do Sul (UFRGS), socializando pesquisas sobre a formação do formador e o processo de acompanhamento, mentoria, tutoria, trazendo os autores de outros países para as rodas das discussões, foram procedimentos possíveis. O atendimento a esta agenda de formação contou, especialmente, com a contribuição de uma mestranda, que participou ativamente, auxiliou na organização dos encontros e providenciou o registro de todos eles, o que resultou em sua pesquisa que abordou sobre o desenvolvimento profissional do professor experiente no projeto colaborativo OBEDUC/UFMT. Novamente a execução da agenda resultou no trabaIho da gestão do projeto na busca do referencial bibliográfico e dos convites a formadores do CEFAPRO, 


\section{autêntica}

do PPGEdu e da SEMED para auxiliarem na parceria da formação. Assim, redes e pesquisa novamente se entrelaçaram no OBEDUC/UFMT.

Os estudos contribuíram grandemente para delinear o perfil do professor experiente no processo de acompanhamento, entre os quais citam-se alguns teóricos como Passeggi e Gaspar (2013), que definem o profissional que acompanha o professor iniciante em seus dilemas e desafios como o professor Orientador. Já de acordo com Beillerot (1996) e Vaillant (2003), Matsuoka (2015) e Mizukami e Nono (2006), este professor pode ser chamado de formador do formador.

Passeggi e Gaspar (2013, p. 65) possibilitam compreender o significado do trabalho coletivo entre professor experiente e professor iniciante ao apresentarem o significado da palavra companheiro, como derivada do latim "cum panis (com pão) que sugere a ideia de compartilhar com o outro o pão. Acompanhar, então, significa caminhar ao lado de alguém que se tornou companheiro(a) e com ele compartilhar o 'pão e o passo'."

Nesse sentido, é possível dizer que o acompanhamento é um movimento de aprender a ser entre companheiros que compartilham entre si seus saberes nas diferentes fases da vida do professor. Observa-se que, na pesquisa, os professores experientes podem ser considerados, conforme a compreensão de Mizukami, Reali e Tancredi (2012, p. 4), como aqueles que dão apoio e auxílio ao professor iniciante "[...] localizam/sugerem materiais, orientam sobre práticas e construção de soluções aos problemas vivenciados pelos iniciantes, partilham experiências." Estes profissionais, com maior experiência na escola realizam "interações qualitativamente significativas", afirmam as autoras. Ureta (2009) define o professor tutor, no caso desta pesquisa o experiente, como sendo aquele que sabe intervir, devido a sua experiência profissional, sabe utilizar atitudes profissionalmente válidas e coletivamente aceitas, sabe relacionar-se, entre outras caraterísticas profissionais.

Para Carlos Marcelo (1999, p. 125), os experientes então denominados mentores devem ser mestres na competência do ensino e agradáveis com relação aos outros professores. Conforme o autor, os mentores deveriam ter a qualidade de "bons ouvintes, com facilidade de comunicação, sensíveis às necessidades dos professores principiantes".

Aponta Mizukami e Reali $(2005$, p. 3) que os formadores "são todos os profissionais envolvidos nos processos formativos da aprendizagem da docência de futuros professores ou daqueles que já estão desenvolvendo algumas atividades docentes." Para Matsuoka (2015), ao formador de formador cabe compreender que na aprendizagem do adulto e, consequentemente, na formação do adulto professor, "é por meio de estratégias de grupos que ocorrem as interações entre adultos e fomentam-se as interpretações e a construção de sentidos com o compartilhamento de experiências, que acabam se tornando significados partilhados." Conforme a autora, o professor formador do formador constrói seus conhecimentos a partir de sua experiência de professor e de formador, buscando articular estas diferentes práticas.

André et al. (2010) afirmam que, além das atividades do professor formador, outra lhe é atribuída, qual seja, a de motivar os professores iniciantes para o exercício da docência, pois, diante dos muitos desafios, da falta de condições de trabalho, de uma carreira sem reconhecimento social, tem-se um alto índice de desistência da profissão.

É importante destacar que, a partir dos estudos coletivos, mestrandos, professores experientes, iniciantes e graduandos organizaram textos, associando referenciais teóricos às suas práticas e às investigações e, assim, estruturam suas produções e participam de eventos com o grupo de pesquisa OBEDUC/UFMT. 


\section{autêntica}

Diante do exposto, pode-se observar que nem sempre são garantidas as condições para que o experiente desempenhe a função de acompanhamento ao iniciante. A mudança do horário, a ausência de um tempo destinado à função e à formação têm dificultado o atendimento em algumas escolas.

A seguir, extraídos de algumas pesquisas, seguem alguns recortes de dados coletados junto com os experientes, associando na amostra os instrumentos adotados.

O Projeto tem nos formado de uma maneira tão sólida que acredito que nunca mais olharemos para os professores iniciantes como antes. [...] Penso que, se o professor experiente se colocar como parceiro, deixar bem claro para ele de sua função, de sua formação, da necessidade que ele tem de ter um acompanhamento no início da carreira, e, principalmente, da responsabilidade de todos com a educação, esse processo de acompanhamento trará grandes resultados. (Memorial de formação, Reflexão, set.2016 - In: SOUZA, 2017).

Então diante de situações preocupantes com a nossa vivência na escola, os colegas, sugeriram o tema sobre a sexualidade, desta vez com a professora Dra. Raquel Salgado da UFMT/CUR. Este encontro rendeu, pois é um tema difícil de ser explorado pela nossa cultura, o meio em que vivemos e deixamos passar também por não dominarmos o assunto e tampouco lidar com conflitos de adolescentes e crianças que, por tantos fatores, estão explorando seu corpo e se descobrindo, pra mim é um tanto assustador e a professora de Psicologia Infantil me fez refletir quando disse que "não existe receita de como tratar a sexualidade... O melhor remédio é a conversa"... "Será que o que nossos olhos veem realmente é o que as crianças sentem ou pensam? [...] Voltei para casa com a pulga atrás da orelha, pensando onde estava a malícia - nos meus ou nos olhos das crianças? No encontro seguinte assistimos ao filme o qual relatava a história de uma criança em conflito com sua sexualidade [...]. (Damata, Memorial/2016. In: ROCHA, 2016).

Primeiro esta formação me levou a refletir sobre o que é aprendizagem, como a sociedade e também a escola percebem a aprendizagem. Mas, aprendizagem de quem? É somente o aluno que precisa aprender, e aprender o quê e como? Estar no OBEDUC já responde a uma das questões. Sei que existem muitos alunos que simplesmente passam pela escola e não aprendem a ler e escrever. Isso é angustiante, porque ler e escrever são o princípio da função escolar. Mas, por que eles não aprendem é o que buscamos saber.[...] Aí que buscamos, junto à família, razões para que se compreenda o não aprender. Por isso devemos ter cuidado, porque na ânsia para justificar o que não fomos capazes de realizar, incorreremos no risco de rotular uma criança com uma determinada patologia [...] (Entrevista narrativa dialogada - Professora Esmeralda, dez.2016.In: LORENZZON, 2017).

Os excertos evidenciam as reflexões dos experientes a partir da formação por eles agendada no OBEDUC/ UFMT. Assim, é possível afirmar que quando redes são articuladas no atendimento às expectativas dos professores sobre sua formação, e a pesquisa está imbricada nestas relações, ampliam-se as reflexões e as possibilidades de aprendizagem coletiva por meio das interações e da itinerância - ora se aprende na/com a escola, ora no campo, ora na universidade, ora nas interações da formação continuada coletiva e ora nos estudos com os grupos de pesquisa. 


\section{autêntica}

\section{AINDA SEM CONCLUIR...}

A pesquisa em desenvolvimento, referente ao projeto OBEDUC do PPGEdu/UFMT, está oportunizando observar os caminhos e desdobramentos possíveis, em Rondonópolis/MT, na formação com graduandos, professores iniciantes e experientes, com enfoque especial no professor em início de carreira, no intuito de considerar seus embates, dilemas e desafios. Busca-se compreender de que maneira os iniciantes percebem a formação por eles agendada, em projeto colaborativo universidade/escola e as suas repercussões na prática docente.

A formação continuada desenvolve-se semanalmente com os graduandos e professores experientes - ora em reuniões específicas de estudos e formação, ora nos encontros coletivos com todos os participantes. Já os professores iniciantes participam da formação quinzenal coletiva.

O processo vivenciado de autoria da agenda de formação parece ser o grande mote que sustenta a motivação e permanência dos professores iniciantes nas ações desenvolvidas pelo projeto. Apresenta-se muito evidente, nas narrativas, que os encontros de formação dos graduandos tocaram suas reflexões, mobilizando conhecimentos que puderam ser associados a outras disciplinas e à produção de textos em pesquisas com os mestrandos. A formação com os graduandos em grupos de pesquisa e, neste caso, partilhando as dificuldades e angústias com os iniciantes em espaços coletivos, contribuiu para que pudessem ampliar o conhecimento sobre a profissão docente, principalmente nos anos iniciais da docência e sinalizou suas pesquisas do TCC.

Por sua vez, a formação em rede dos professores iniciantes e experientes implicou mudanças significativas nas práticas das investigadas, evidenciando reflexões que foram levantadas gerando indagações e pesquisas na própria escola.

Uma das evidências reveladas na pesquisa é a de que se deve devolver a autoridade da gestão da formação aos professores no espaço da escola e em projetos colaborativos, de forma que possam reconhecer-se como legítimos interessados na gestão do que lhes é mais necessário ao desenvolvimento profissional docente. Os temas da formação, quando a agenda é dos professores, surgem do cotidiano e das dificuldades enfrentadas na prática, sendo, portanto, legítima e defendida pelos iniciantes. Por sua vez, a formação destes torna-se mais fecunda quando resulta da articulação de suas redes de ensino e da gestão, em projetos colaborativos entre a universidade e escolas.

\section{REFERÊNCIAS}

ANDRÉ, Marli E. D. A. et al. Os saberes e o trabalho do professor formador num contexto de mudanças. Anais da 33a reunião da Anped/2010. Disponível em: < http://33reuniao.anped.org.br/33encontro/app/webroot/ files/file/Trabalhos\%20em\%20PDF/GT08-6743--Int.pdf> acessado em 2015.

ANDRÉ, M. et al. O papel do outro na constituição da profissionalidade de professoras iniciantes. Revista Eletrônica de Educação, v.11, n.2, p. 505-520, jun./ago., 2017. Disponível em: <http://www.reveduc.ufscar. br/index.php/reveduc/article/view/2231>. Acesso em: 20 set. 2017.

BEILLEROT, Jacky. La Formacion de Formadores: entre la teoria y la práctica. Buenos Aires-Argentina: Ediciones Novedades Educativas, 1996.

BRASIL. Ministério da Educação. Observatório da Educação/CAPES/INEP/SECADI. Projeto submetido e aprovado no Edital 49/2012. Projeto 24232 Egressos da Licenciatura em Pedagogia e os desafios da prática 


\section{DOCENTE}

autêntica

em narrativas: a universidade e a escola em um processo interdisciplinar de inserção do professor iniciante na carreira docente, UFMT/PPGEDU/Câmpus Universitário de Rondonópolis.

CARDOSO, F.M.; SILVA, A. P.; SOUZA, C. R. G.. Formação Inicial para além da Sala de Aula: grupos colaborativos e aprendizagens formativas de graduandas da pedagogia. In: II Seminário Formação Docente: intersecção entre universidade e escola necessidades formativas nas/das licenciaturas. 12 a 14 de Junho. Anais... UEMS MS - Dourados. Disponível em: https://www.geppef.com.br/seminario. Acesso em: 31 ago.,, 2017.

DAY, Christopher. Desenvolvimento profissional de professores: os desafios da aprendizagem permanente. Tradutora: Maria Assunção Flores. Portugal: Porto Editora, LDA. 2001.

GATTI, B. A.; BARRETO, E. S. de S.; ANDRÉ, M. E. D. de A. Políticas docentes no Brasil: um estado da arte. Brasília: UNESCO, 2011.

GABARDO, Cláudia Valéria; HOBOLD, Márcia de Souza. Início da docência: investigando professores do ensino fundamental. Form. Doc., Belo Horizonte, v. 03, n. 05, p. 85-97, ago./dez. 2011.

FRANÇA, Márcia Socorro dos Santos. O desenvolvimento profissional dos professores iniciantes egressos do curso de licenciatura em Pedagogia: um estudo de caso. Rondonópolis, MT: UFMT. 138 f. 2016. Dissertação (Mestrado) Universidade Federal de Mato Grosso, Instituto de Ciências Humanas e Sociais, Programa de Pós-Graduação em Educação. Rondonópolis, 2016.

HUBERMAN, M. O ciclo de vida profissional de professores. In: Nóvoa, A. (org.) .Vida de professores. Portugal: Porto Editora. 2013.

IMBERNÓN, Francisco. Formação continuada de professores. Tradução Juliana dos Santos Padilha. Porto Alegre: Artmed, 2009.

Formação docente e profissional: formar-se para a mudança e a incerteza. Tradução: Silvana Cobucci Leite. 9 ed. São Paulo: Cortez, 2010.

LORENZZON, Marcia Roza. Narrativas dialogadas nos diários de campo reflexivos de professores iniciantes: possibilidades de autoformação.Dissertação de Mestrado- Universidade Federal de Mato Grosso, Instituto de Ciências Humanas e Sociais, Programa de Pós-Graduação em Educação, Rondonópolis, MT, 2017.

MARCELO, Carlos. Formação de Professores: para uma mudança educativa. Portugal: Porto Editora, 1999.

Desenvolvimento Profissional Docente: passado e futuro. Revista de Ciência da Educação, 08, Jan/ abr. 2009, p. 7-22. Disponível em: <132.248.192.201/seccion/bd_iresie/iresie_busqueda.php? indice...>. Acesso em: 02 abr. 2014.

O professor iniciante, a prática pedagógica e o sentido da experiência. Revista Brasileira de Pesquisa sobre Formação Docente. Belo Horizonte, v. 03, n. 03, p. 11-49, 3156 ago./dez. 2010. Disponível em:

< http://formacaodocente.autenticaeditora.com.br>. Acesso em: 23 jul. 2015

MARCELO, Carlos. VAILLANT, Denise. Desarrollo professional docente: como se aprende a enseñar? 3. ed. Madrid/España: Narcea, 2013. 


\section{autêntica}

MATSUOKA, Sílvia de Oliveira. A formação de Professores Formadores do Cefapro-MT: desenvolvimento e identidade profissional. Tese de Doutorado em Educação: Psicologia da Educação. PUC/São Paulo, 2015.

MIRA, Marília Marques; ROMANOWSKI.Joana. Programas de inserção profissional para os professores iniciantes: uma análise da produção científica do IV Congresso Internacional Sobre Professorado Principiante e Inserção Profissional à docência. In: X ANPED SUL, 2014, Florianópolis. Anais ... Florianópolis, 2014, p. 1-19. Disponível em:<http://xanpedsul.faed.udesc.br/arq_pdf/75-0.pdf>. Acesso em: fev. 2015.

MIZUKAMI, Maria da Graça Nicoletti et al. Escola e aprendizagem da docência: processos de investigação e formação. São Carlos: EdUFSCar, 2002.

MIZUKAMI, Maria da Graça Nicoletti. Aprendizagem da docência: algumas contribuições de L. S. Shulman. Revista Educação, Vol. 29, nº 02, jul./dez. 2004 2004.UFSM

MIZUKAMI, Maria da Graça Nicoletti; REALI, Aline Maria de M. Rodrigues. Práticas profissionais, formação inicial e diversidade: análise de uma proposta de ensino e aprendizagem. In: MIZUKAMI, Maria da Graça Nicoletti; REALI, Aline Maria de M. Rodrigues. Aprendizagem profissional da docência. São Carlos: EdUFSCar, 2005.

MIZUKAMI, Maria da Graça Nicoletti; REALI, Aline Maria de M. Rodrigues; TANCREDI, Regina Maria Simões Puccinelli. Mentores e Professores Iniciantes em Interação: possibilidades formativas da educação online. Revista Cet, vol. 01, nº2, abril/2012.

NACARATO, A. A parceira universidade-escola: utopia ou possibilidade de formação continuada no âmbito das políticas públicas. Revista Brasileira de Educação, Rio de Janeiro: ANPEd, vol.21, n.66, p. 699-716, jul-set. 2016.

NONO, Maévi Anabel; MIZUKAMI, Maria da Graça Nicoletti. Processos de formação de professores iniciantes. UNESP e UFSCar, 2006. Anais... Disponível em:

<http://29reuniao.anped.org.br/>. Acesso em: nov. 2014

NÓVOA, António. Formação de professores e trabalho pedagógico. Lisboa: Educa, 2002.

Professores Imagens do futuro presente. Lisboa: EDUCA, 2009.

PASSOS, L. F.. Práticas Formativas em Grupos Colaborativos: das Ações Compartilhadas à Construção de Novas Profissionalidades. In: André, M. (Org.) Práticas Inovadoras na Formação de Professores. Papirus Editora. 2016.

PASSEGGI, Maria Conceição. Memorial de formação. In: OLIVEIRA, D.A.; DUARTE, A.M.C.; VIEIRA, L.M. F. DICIONÁRIO: trabalho, profissão e condição docente. Belo Horizonte: UFMG/Faculdade de Educação, 2010. CDROM

PASSEGGI, M. C.; GASPAR, M. M. G. Acompanhamento e dispositivos de mediação biográfica: memorial de formação, grupos reflexivos e diário de acompanhamento. In:

PASSEGGI, Maria Conceição; VICENTINI, Paula Perin; SOUZA, Elizeu Clementino. Pesquisa (Auto)biográfica: Narrativas de si e formação. Curitiba: CRV, 2013. p. 63-81. 
PASSEGGI, Maria Conceição et al. Formação e pesquisa autobiográfica. In: SOUZA, Elizeu Clementino de, (Org.). Autobiografias, histórias de vida e formação: pesquisa e ensino. Porto Alegre: EDIPUCRS, 2006.

REALI, A. M. M. R.; MIZUKAMI, M. G. N. Desenvolvimento profissional da docência: teorias e práticas (org.). São Carlos: EduFCar, 2008.

ROCHA, Simone Albuquerque; ANDRÉ, Marli E. A. D. de. Os memoriais na licenciatura: narrativas dos entre-espaços da formação docente. In: ROCHA, Simone Albuquerque da. Formação de professores: licenciaturas em discussão. Cuiabá: EDUFMT, 2010.

ROCHA, Simone Albuquerque da. O grupo investigação e os desdobramentos

possíveis na sua trajetória de pesquisa. I/ Simpósio de grupos de pesquisa sobre formação de professores do Brasil. GT 8 Anped. Guarulhos, 2016. Disponível em:< http://www.anped.org.br/news/iii-simposio-de-grupos-de-pesquisa-sobre-formacao-de-professores-do-brasil-03-e-04-de-outubro/2016>. Acesso em: 10 de dezembro de 2016.

SOUZA, Sueli de Oliveira. Desenvolvimento profissional do professor experiente no projeto colaborativo universidade/escolas: desafios e necessidades formativas. Dissertação (mestrado) - Universidade Federal de Mato Grosso, Instituto de Ciências Humanas e Sociais, Programa de Pós-Graduação em Educação, Rondonópolis, 2017.

TARDIF, M. Saberes docentes e formação profissional. 9. ed. Petrópolis, RJ: Vozes, 2008.

TARDIF, Maurice; LESSARD, Claude. O trabalho docente: elementos para uma teoria da docência como profissão de interações humanas. 9. ed. Petropolis/RJ: Vozes, 2014.

URETA, Consuelo Vélaz de Medrano. Competências del Professor-Mentor para el acompanhamento al profesorado principiante. Profesorado-Rev.de currículum y formación del professorado, Madri/Espanha, v. 13, n. 1, 2009. p. 209-229.

VAILLANT, D. Formação de formadores: estado da prática. Documento do Programa de Promoção da Reforma Educativa na America Latina e Caribe - PREAL, no.25, outubro,2003.

VAILLANT, Denise; MARCELO, Carlos. Ensinando a ensinar: as quatro etapas de uma aprendizagem. Curitiba: Ed. UTFPR, 2012. 